PDFlib PLOP: PDF Linearization, Optimization, Protection

Page inserted by evaluation version www.pdflib.com - sales@pdflib.com 


\title{
The Uses of the Stranger: Circulation, Arbitration, Secrecy, and Dirt*
}

\author{
Nedim Karakayali \\ Bilkent University
}

\begin{abstract}
Little attention has been paid to the role of strangers in the social division of labor that is otherwise a key concept in sociological theory. Partly drawing upon Simmel, this article develops a general framework for analyzing the "uses" of "the stranger" throughout history. Four major domains in which strangers have often been employed are identified: (1) circulation (of goods, money, and information); (2) arbitration; (3) management of secret/sacred domains; and (4) "dirty jobs." The article also explores how these activities relate to the characteristics of stranger-relations. It is suggested that such an inquiry, in addition to helping us to understand how the presence of strangers in a society affects the processes of social differentiation, might equip us with a conceptual framework often lacking from purely political and ethical considerations of stranger-relations.
\end{abstract}

At least since Comte, many social theorists have underlined that division of labor is not merely an economic but also a social and moral phenomenon. Durkheim, as well known, viewed division of labor as one of the main sources of social life, and argued that many types of social relations, including friendship, ${ }^{1}$ can partly be explained through this key concept (Durkheim 1964:54-56). The connections between division of labor and stranger-relations, however, received little attention in the classical literature - even Simmel, whose observations constitute a major inspiration for this article, did not go beyond a few passing remarks on the matter. The issue has not been rigorously explored in the contemporary literature either. With a few exceptions, most recent contributions to the literature on "the stranger" focus on symbolic, ethical, and political aspects of stranger-relations (Bauman 1991; Derrida 2000; Diken 1998; Girard 1986; Harman 1988; Kristeva 1991). Conversely, the "rediscovery of division of labor" (Garnsey 1981) in the contemporary literature does not involve a "discovery" of the role of strangers in that process. ${ }^{2}$

This curious gap in sociological theory is rather unfortunate since, as I attempt to show in this study, stranger-relations are no more explicable than relations of friendship without some reference to division of labor. An inquiry into the role of strangers in the division of labor might help us to understand not only the major motivations behind stranger-relations, but also how the presence of strangers in a society affects the processes of social differentiation.

\footnotetext{
*The author wishes to thank the anonymous reviewers for their valuable comments. Address correspondence to: Nedim Karakayali, Department of Political Science, Bilkent University, 06800 Bilkent, Ankara-Turkey. E-mail: nedim@bilkent.edu.tr.

${ }^{1}$ For a detailed discussion of Durkheim's views on "friendship," see Wallace and Hartley (1988).

${ }^{2}$ The only allusion to a link between strangeness and division of labor is made in the context of ethnic and cultural division of labor. See, for example, Hechter (1978), Hughes (1928).
} 
Perhaps the best way to clarify our problem is to start with Margaret Wood's (1934) observations in her little-known book, The Stranger. ${ }^{3}$ In this study, Wood notes that people who try to join a group from outside might face three distinct reactions: they might simply be expelled; they might be adopted unconditionally; or they might be accepted to the group conditionally. This third possibility, Wood further points out, coincides with Georg Simmel's description of "the stranger." As well known, in a brief excursus in his Soziologie, Simmel (1971a) defines the stranger as someone who is accepted to a group as a member but who nevertheless remains detached from it. He invites the reader to think of the stranger's relation to his/her group as a unique synthesis of nearness and distance, and briefly comments on some of the surprising implications of such a relationship.

But why are there "strangers"? As absurd as this question might first sound, it is worth noting that the options of expulsion and adoption require much less "effort," much less institutionalization, and are likely to lead to much fewer complications than stranger-relations. What motivates (or compels) people to enter into, as Simmel puts it in a slightly different context, "[h]alfway, unclear relations ... which have their root in a twilight condition of feeling whose outcome might be hatred almost as easily as love, or whose undifferentiated character is even sometimes betrayed by oscillation between the two" (Simmel 1971c:80)?

In attempting to answer this question, one specific observation that can be drawn from Simmel's work might be helpful: strangers often carry out special tasks that no one else in the group is capable of (or willing to) perform. This happens precisely because strangers are neither fully absorbed into the group, nor fully excluded from it.

Beyond this general proposition, Simmel's work can also provide clues for exploring the specific domains in which strangers are most likely to be active, and for explaining how these activities relate to the characteristics of stranger-relations. Partly drawing upon the empirical examples provided by Simmel, I can identify four major domains: (1) circulation (of goods, money, and information); (2) arbitration and conflict resolution; (3) management or policing of secret/sacred domains; and (4) cleansing the group from its impurities or, more generally, "dirty jobs." The first three of these domains can be deduced from Simmel's work but the fourth one, which has become the most prevalent domain of activity for strangers in the 20th century, seems to have escaped his attention. In exploring this domain, I will try to point out some of the limitations of Simmel's conceptualization and suggest ways in which it can be modified to analyze contemporary stranger-relations.

It is important to note that Simmel has not developed these observations systematically. And while there are highly valuable studies (Coser 1972; Shack and Skinner 1979) in the subsequent literature on the activities of strangers in particular domains, a comprehensive theoretical framework does not exist. In what follows, I will first provide a brief introduction to Simmel's theoretical terminology, ${ }^{4}$ focusing particularly

\footnotetext{
${ }^{3}$ Little information is available about Margaret Mary Wood, whose work is not widely cited in the sociological literature. As we learn from the Vita appended to her book on the stranger, she was born in 1888 in Cheyenne, Wyoming and led a rather nonsedentary life since her childhood, teaching in many schools in the United States and abroad (including the Philippines and Turkey). She has published several articles in social psychology and social science journals, and two books, one on strangeness and the other on loneliness (Wood 1953).

${ }^{4}$ It is impossible to give a full account of Simmel's sociological theory in the limited space of this article. For a general discussion of Simmel's work, see Frisby (1981, 1992), Habermas (1996), Kaern, Philips, and Cohen (1990), Poggi (1993). As several scholars have pointed out recently, although Simmel's brief excursus on "the stranger" has been one of the most oft-cited texts in the history of sociology, this has not always entailed a rigorous analysis of Simmel's arguments. For critical discussions of Simmel's concept of the stranger, see Alexander (2004), Karakayali (2003a, 2003b), Levine (1977), McLemore (1970).
} 
on his distinction between "forms" and "contents" of social interaction, which is essential for specifying the theoretical basis of the question at hand. I will then discuss the four domains of activity mentioned above. Finally, I will try to sketch out the broader theoretical implications of this discussion, pointing out some of the ways in which the role of strangers in the social division of labor interacts with symbolic and political dimensions of strangeness.

\section{PROBLEMS AND SOLUTIONS: STRANGENESS AS A FORM OF INTERACTION ${ }^{5}$}

For Simmel, strangeness is a "form of interaction." The most rigorous discussion of Simmel's distinction between "form" and "content" can be found in his writings on the philosophy of history (Geschichtsphilosophie) (Simmel 1977, 1980), which Weber (1969:3; 1975) characterizes as one of the founding texts of Verstehensoziologie. ${ }^{6}$ Here, Simmel's main suggestion is that the forms through which historical phenomena become "meaningful" are similar to what Kant considers as the a priori categories of the mind through which the knowledge of nature becomes possible.

Unlike Kant, however, Simmel does not locate historical forms in a transcendental plane but rather views them as being immanent to social life (see also Oakes 1980:3). In his sociological essays, he describes the relation between "content" and "form" as being isomorphic to the relation between an "interest" and its realization. Human beings "sociate" because "[s]ociation is the form.... in which their interests are realized" (Simmel 1971d:24). Human beings produce social forms, while pursuing a certain "drive, interest, purpose, inclination, psychic state, movement" (Simmel 1971d:24). In The Philosophy of Money, Simmel (1990:212) suggests that social forms are essentially tools. Just as human beings create tools in order to realize their desires vis-à-vis nature, so do they create forms of interaction like exchange, cooperation, division of labor, and so on to realize their interests vis-à-vis each other. From a broader point of view, then, the content can be interpreted as the locus of problems that find their solutions in particular forms (themselves always problematic and partial). Given that for Simmel strangeness is also a form of interaction, we can ask: What kind of problem(s) does such a form "solve"?

From the perspective of the stranger, the answer to this question seems rather obvious. More often than not, people become strangers either because they have no other choice, or, less dramatically, because they are in pursuit of a better life. The question of "motivation," however, is more complicated in the case of the "majority" who, at least at first sight, has much more freedom in deciding between the options of expelling, assimilating, or entering into a "halfway relation" with newcomers. The story of the stranger almost always begins with the "permission" of the political authorities in the group, who, in fact, in many cases, actively invite or recruit outsiders. ${ }^{7}$

\footnotetext{
${ }^{5}$ Throughout this text, I use the term "strangeness" as a standard translation of the German word Fremdsein as used by Simmel. In Simmel's usage, Fremdsein does not so much mean "being strange" but it refers to a "form of interaction" or the condition of being involved in such an interaction. While the term might also be used for referring to a "quality" of an object (e.g., the strangeness of ...), given Simmel's radically relational approach, there is no such thing as "being strange" without being involved in a stranger-relation.

${ }^{6}$ Guy Oakes's (1980) introduction to Simmel's essays on historical understanding is so far the best account of Simmel's philosophy of history in English.

${ }^{7}$ This is not to undermine the importance of "illegal immigration," which is often presented as one of the most serious issues in present-day Western societies. However, the attitude of political authorities toward illegal immigrants, whose economic contribution is not insignificant, can be far more ambivalent than what is usually assumed. See, for example, Calavita (1994).
} 
The decision of authorities to accept a group of newcomers as conditional members is seldom univocally shared by all group members. In most, if not all, cases the main encounter of the stranger is not with the society as a whole but with those groups that have relatively large political or economic capital: tribal chiefs, kings, states, colonial administrators, and so on. As a result, the acceptance (or recruitment) of the stranger to the group depends on whether his/her presence is beneficial to these agents. It should, therefore, not surprise us that the stranger often appears as what Coser (1972) has called a "servant of power" - a point that was already observed by Simmel (1950) in his essay on domination and subordination.

This, however, does not mean that we can explain the development of strangerrelations by simply looking at the subjective interests of powerful groups. In fact, in some cases, the political authorities in the group are themselves quite powerless in the face of various legal or moral constraints. The acceptance of refugees to Germany since the late 1970s, for example, was facilitated by laws that were created for entirely different purposes after World War II (Münz and Ulrich 1998). Historical records show that gypsies arriving in Europe often avoided expulsion by presenting themselves as "pilgrims" (Fraser 1992).

Even when such legal or moral imperatives are missing, the subjective interests of powerful groups can become fully intelligible only within the broader context in which they emerge. At first sight, a historical survey of such contexts would provide a rather chaotic picture. The problems that are solved through the acceptance of strangers display an enormous diversity. When the King of France invited the Jews to his kingdom in the 14th century, renewing the contract that his father had annulled, he was hoping, among other things, to fill his treasury (by the taxes he would receive from the returning Jews) without overexploiting the native population of his kingdom (Jordan 1997). Ottoman Sultans recruited non-Muslim children to their elite army, assuming that such an army would be more loyal to them than one constituted by native soldiers (Coser 1972). Western colonial powers recruited foreigners as middlemen and tax collectors so that they could avoid a direct confrontation with the colonized peoples they ruled (Bonacich 1973; Leighton 1979). Examples can easily be multiplied.

The problems solved through the establishment of stranger-relations, then, vary enormously from one sociohistorical context to the other. Nevertheless, Simmel's work implies that behind this variation we can observe a recurrent pattern. This pattern, as mentioned above, involves the asymmetrical distribution of tasks between strangers and "native" members of a group. Strangers are often excluded from those domains of activity that are open to "native" members while they tend to be active in those domains that other members are either unable or unwilling to participate. In what follows, I will look more closely at four such domains that have typically been occupied by strangers. While discussing each domain, I will try to show how the activities in these domains relate to the characteristics of stranger-relations.

\section{CIRCULATION}

The first general domain of activity in which strangers participate is circulation (of goods, money, and information). Simmel's example that corresponds to this domain is the trader in ancient societies: "In the whole history of economic activity the stranger makes his appearance everywhere as a trader, and the trader makes his as a stranger" (Simmel 1971a:144). I will soon discuss the importance of the symmetrical form of this statement. But let me first note that "the trader" in this passage refers 
to a historically specific category, namely, the cross-cultural trader in preindustrial societies:

As long as production for one's own needs is the general rule, there is no need for a middleman within the group. A trader is required only for goods produced outside the group. Unless there are people who wander out into foreign lands to buy these necessities, in which case they are themselves "strange" merchants in this other region, the trader must be a stranger; there is no opportunity for anyone else to make a living at it. (Simmel 1971a:144)

The most typical example of Simmel's trader is someone who settles down in a "closed economic group" that nevertheless can or will provide opportunities for "livelihood for the trader" (Simmel 1971a:144). ${ }^{8}$ People who were involved in random "border trade" in preurban societies as well as the traders in the context of industrial capitalism (where production for the market is the rule), for example, are not included in this category.

Understood in this way, Simmel's statement is supported by recent studies on the history of cross-cultural trade. In ancient Greece, for example, the first regular trade activities seem to have emerged in "boundary markets." With the growth in urban areas around the eighth century BC, however, these boundary markets began to disappear. Instead, "[e]arly urban markets tended to appear near the heart of the city... presumably because the traders wanted to have the best possible access to potential customers" (Curtin 1992:2). This development signaled the emergence of the trader as the stranger:

[T] he most common institutional form after the coming of city life was the trade settlement. Commercial specialists would remove themselves physically from their home community and go to live as aliens in another town .... There the stranger merchants could settle down and learn the language, the customs and the commercial ways of their hosts. They could then serve as cross-cultural brokers, helping and encouraging trade between the host society and people of their own origin who moved along the trade routes. (Curtin 1992:2)

This rather sketchy discussion might give the impression that traders usually end up as strangers merely because they have to live in a foreign society. For Simmel, however, the relationship between strangeness and trade has a more complex and reciprocal nature: "not only is the trader a stranger, but the stranger is also disposed to become a trader" (Simmel 1990:225). That strangers as well as certain ethnic minorities in preindustrial societies have a disposition to be involved in trade, and more generally in the financial sector, Simmel notes, is demonstrated by numerous historical cases: metics in ancient Greece, Jews in Europe, Moors in Spain, Parsees in India, and so on. (Simmel 1990:221-23).

Given the enormous diversity of these groups, it is clear that this "disposition" cannot simply be derived from their ethnic, cultural, or religious background. Thus, Simmel maintains that this "disposition" is not so much located in strangers as such but rather in the specific relationship they have to their social environment: "Dispersed peoples, crowded into more or less closed cultural circles, can hardly put

\footnotetext{
${ }^{8}$ Already here one might note a certain similarity between Simmel's stranger and Michel Serres's (1982) "parasite." I will return to this point in the conclusion.
} 
down roots or find a free position in production. They are therefore dependent on intermediate trade which is much more elastic than primary production" (Simmel 1990:225). Strangers, in other words, are disposed to take part in circulation of economic goods because of their "mobile" status vis-à-vis the group.

More generally, Simmel explains this mobility through his definition of the stranger as an extraneous element "who intrudes as a supernumerary, so to speak, into a group in which all the economic positions are already occupied" (Simmel 1971a:144). In fact, these positions are not merely "occupied" but are often also denied to strangers. The following passage shows quite clearly that, for Simmel, it is the denial of land ownership and political rights as well as lack of social capital that underlie the "attraction" of strangers to trade and "money":

The role that the stranger plays within a social group directs him, from the outset, towards relations with the group that are mediated by money, above all because of the transportability and the extensive usefulness of money outside the boundaries of the group.... The stranger as a person is predominantly interested in money for the same reason that makes money so valuable to the socially deprived: namely, because it provides chances for him that are open to fully entitled persons or to the indigenous people by specific concrete channels and by personal relationships. (Simmel 1990:224)

Moreover, the denial of certain rights to strangers often runs parallel to the unwillingness or inability of group members to occupy a different position than they are used to (or, to engage in the type of activities that are "spared" to strangers). As Simmel (1990:225) notes, such "denial" therefore often works in both directions: "the citizens in Plato's Laws are prohibited from owning gold and silver, and all trade and manufacturing is specifically reserved for strangers"-needless to add, Plato's proposition reflects the Greek worldview of his time. In this sense, the "disposition" of the stranger to be involved in trade and the financial sector is inextricably tied to the "disposition" of natives to stick to their traditional activities. As Curtin (1992:6) puts it, "[w]here commerce was regarded as such an unpleasant occupation, it was seen as better left to foreigners."

The "logic" of the stranger's involvement in the financial sector, then, is just a particular example of the mutually exclusive distribution of tasks between strangers and "native" members of a group. The role of strangers in circulation extends to the flow of other, less tangible but nevertheless essential items such as information, technology, knowledge, ideas, and beliefs. As artisans and craftsmen, for example, they were instrumental in the dissemination of technological know-how in ancient societies (more on artisan-strangers later). In fact, under certain circumstances, we are likely to observe a reciprocal relation between the stranger and the "teacher." Some of the most notable Greek philosophers (e.g., Aristotle) were metics. Simmel himself had to leave his hometown Berlin for an academic position in Strasbourg. ${ }^{9}$ Margaret Wood, who taught in public schools and abroad, notes that her first-hand experience with strangeness was due to her profession (Wood 1934). Almack, Cook, and Greenhoe (1938) argue that the case of public school teachers who migrate "from the anonymity of the campus" to the "small-town community" where they turn into the focus of attention can best be analyzed through the concept of the stranger.

\footnotetext{
${ }^{9}$ For a brief discussion of this event, see Habermas (1996:405).
} 
The congruence between teaching (and, more generally, "intellectual activity") and strangeness, of course, is not so surprising. As Simmel (1990) shows in The Philosophy of Money, in many ways, "ideas" and "knowledge" are like money: they "belong" to no one, and can belong to anyone; they are easily transportable. Until quite recently, like trade, intellectual activities were far removed from primary production and, especially in ancient societies, they were not much revered by primary producers and the warrior nobility.

At least since Mannheim's (1936) thesis on "floating intellectuals," the congruence between strangeness and intellectual activity has been a significant theme in the sociological literature. This congruence should nevertheless be carefully qualified. Especially in Mannheim's work the "distance" of intellectuals to their society appears as a source of epistemological privilege - an idea that is implicit also in Simmel's (1971a:146) argument that the stranger is capable of having a "bird's-eye view" of the social relations in his/her group. This thesis, however, has been criticized in the subsequent literature by scholars who point to the conditions that make such a distance possible, and the potential biases that might follow from it. ${ }^{10}$

It is, however, possible to think of the epistemological significance of strangeness in a different light if we take the circulatory role of strangers into account. Rather than portraying the stranger as a subject who has privileged access to a more objective or universal type of knowledge on the basis of a static "distance from society," we might focus on his/her capacity to weave together elements from and open channels of communication between different worlds.

In this context, the case of interpreters is especially revealing. As Shack (1979:47) puts it, "interpreters" are "individuals and groups who stand at the frontiers of conflicting social systems." Strangers in the role of interpreters do not just "translate" words; rather, they "serve to translate material and organizational needs into systems which enable them to be adequately met" (Shack 1979:47). In order to accomplish this properly, interpreters have to be able to move back and forth not just between two "languages" but two cultures. In this sense, as with other middleman professions, the most perfect "interpreter" has to be someone who does not exclusively belong to any of the groups between which she/he facilitates communication, while at the same time being intimately related to both. ${ }^{11}$

\section{ARBITRATION}

The case of interpreters indicates that strangers might also play a role in "conflict resolution." This brings us to the second general domain of activity for strangers, namely, arbitration. Simmel's example in the excursus that corresponds to this domain is the practice of recruiting judges from outside in some medieval city-states. This example refers back to a more general problem that Simmel takes up in the

\footnotetext{
${ }^{10}$ See, for example, Bourdieu and Wacquant (1992), Pels (1999), Karakayali (2004).

${ }^{11}$ In the contemporary literature, several scholars have paid special attention to the potential of the interpreter for epistemological innovation. Through the figure of Hermes - among others, the god of commerce and borders-Michel Serres (1982, 1983) has explored the possibility of a more "dynamic" conception of science and philosophy capable of weaving together elements from separate "spaces" such as myth, art, literature, and science. Such a task, Serres seems to suggest, can only be accomplished by remaining at the intersection of multiple domains and, like Hermes, watching over the barely visible passages between them. In a similar vein, albeit in a very different context, Bauman (1987) has proposed to change the role of the intellectual from that of a legislator who shapes and leads people, to that of an interpreter who facilitates communication and mutual respect between multiple cultures.
} 
third chapter of Soziologie (1908) dealing with domination and subordination. Here Simmel notes that one major form in which a group can be characterized is its "preference for subordination to a stranger or to somebody from its own midst" (Simmel 1950:216). The former option was practiced not only by various German and Italian city-states, but also by rulers such as Louis XI who chose to recruit their higher officials either from abroad or from the lower classes. And even as late as in the 19th century, Simmel notes, political theorists such as Jeremy Bentham advocated this practice, arguing that foreigners would make the best state officials (Simmel 1950:216).

For Simmel, whether a group will choose the former or the latter option is essentially a pragmatic issue; the difference between the two lies in the fact that "the stranger is more impartial; the member is more understanding" (Simmel 1950:216). One crucial factor that affects this preference is the level of internal conflict in a group. Subordination to a stranger "is the more suitable [option] to the extent to which the subordinates are heterogeneous or mutually alien or opposed elements" (Simmel 1950:216). Thus, "the practice in certain Italian cities of recruiting their judges from outside" follows from the fact that "no native was free from entanglement in family interests and factionalism" (Simmel 1971a:145). In the excursus, Simmel further stresses the point that the capacity of strangers to act as leaders, judges, or arbitrators in internally divided groups is inseparable from their particular form of interaction with the group as a whole: "Because [the stranger] is not bound by roots to the particular constituents and partisan dispositions of the group, he confronts all of these with a distinctly 'objective' attitude" (Simmel 1971a:145). It is not a coincidence that the term "objective" appears here in quotation marks. For the "objectivity" of the stranger is "an attitude that does not signify mere detachment and non-participation, but is a distinct structure composed of remoteness and nearness, indifference and involvement" (Simmel 1971a:145). In fact, if the stranger can function as an arbitrator, this is because he also has something in common with both groups and forms a kind of "reference" point with respect to them: "what is common to both parties (the basis, that is, of their conflict as well as of their possible reconciliation), must somehow be inherent in the arbitrator, or must at least be accessible to him" (Simmel 1950b: 221).

In these respects, Elizabeth Colson's (1966) study on the role of "alien diviners" and "witchfinders" in the Tonga society of Zambia provides an excellent illustration of Simmel's argument (see also Shack 1979). The Tonga of Zambia consult diviners privately concerning numerous issues, but particularly misfortunes such as death, sickness, and accidents. The diviners who come from elsewhere are valued more, since many think that "a man from a distance, knowing nothing of local affairs, is more likely to give a true divination than a local man," but "it may be enough that the diviner is outside the immediate household group"-the important rule is that "a man or a woman should seek a neutral tool; no man may divine his own matter" (Colson 1966:222).

That the diviner should come from outside one's immediate circle is not so surprising given that they are often consulted "to confirm suspicions against kinsmen and neighbors" (Colson 1966:223). This point becomes all the more important in the case of "witchfinders," who are consulted not by individuals or kin groups but by a whole community (e.g., a village). As the name suggests, witchfinders are primarily expected to discover the sorcerers in a community who cause death and misery. The witchfinder must be a stranger because the problem is internal to the group (Colson 1966:223-24). 
We should not, however, think of the "neutrality" of the witchfinder as a kind of "epistemological" privilege that really allows him to discover the sorcerer. As Colson (1966:223) notes, it is more a matter of politics since the "witchfinder is a proclaimer of sorcerers rather than a discoverer. The people have long decided who their local sorcerers are." When (or if) the witchfinder agrees with these implicit accusations, his declaration basically lends credibility to these suspicions and gives them an explicit form so that they can be dealt with publicly.

It is important to note that the role of the witchfinder cannot be played by any "outsider" whatsoever. In order to play this role, the outsider should already be included in the Tonga society and culture. As Colson (1966:228) points out, while "he is uncommitted to any group of contestants ... [h] is not a stranger to the system of beliefs, or standards, that control the situation in which he is called upon to operate." Thus, for example, the Tonga never attempt to involve European colonizers or the chieftains (who are implanted by the colonizers) in such matters.

It is possible to find certain parallels between the above example and the intermediary role played by "third parties" in contemporary international conflicts. Although the parameters that influence the outcome of the latter are much more varied and complex than the former, especially in those types of mediation where the third party is not the representative of a "super-power" that imposes a solution upon the conflicting sides, the role played by this party resembles that of the stranger-arbitrator. The neutrality of the third party is of course a significant factor here. However, this neutrality should not be understood in an "abstract" sense. In fact, it has been pointed out that mediators who have a similar background to the conflicting sides, such as belonging to the same religion or bloc, tend to be more successful than unrelated parties (Bercovitch and Houston 1996:28). This might be related to the genuine desire of the third party to maintain stability in the region, which makes him/her more trustworthy, but it also seems to have much to do with this party's capacity to facilitate communication. As Princen (1992:10) puts it, "[1]eaders in conflict seek out third parties to gain - and, possibly, to reveal-information necessary for settlement." Furthermore, the more the neutrality of the third party is believed, the easier it becomes for the leaders on the conflicting sides to justify the concessions they make in public (Princen 1992:9). Of course, the "personality" and "skills" of the mediator can make a difference. But, ultimately, in some cases of international mediation, as in the case of alien diviners, the third parties might help settle conflicts due to their position and not because there is something "divine" about them.

\section{SECRECY}

A third domain of activity particularly associated with strangers is the domain of "secrecy" where the term "secret" implies both "private" and "clandestine" as well as "magical" and "mysterious." Simmel's example that corresponds to this domain is the role of the stranger as a "confidant" who "receives the most surprising revelations and confidences, at times reminiscent of a confessional, about matters which are kept carefully hidden from everybody with whom one is close" (Simmel 1971a:145). This third domain is not totally separate from the domains I have identified so far. In fact, the links between secrecy and strangeness are already evident in the examples I have discussed. These links can be analyzed in terms of three closely interrelated forms. First, strangers often work in "secret," private, or "sensitive" domains-as statesmen and elite soldiers, court advisors, confidants, nannies, and domestic workers. Second, they are given exclusive access to-or are supposed to have a privileged 
insight about - the secrets of the group. "Alien diviners," for example, can identify the hidden sources of evil in the group. Even traders (who tap into hidden resources) and interpreters (who reveal hidden meanings) can be considered in these terms. And, finally, strangers as persons are assumed to embody secret qualities. Thus, like the sorcerers they identify, witchfinders themselves are considered to be sorcerers.

The activities of strangers and the objects they "handle" are often attributed a "magical" quality. This is already the case with traders. As Simmel points out in The Philosophy of Money, in the earlier stages of the development of a money economy, the substances from which money is made is assumed to have an intrinsic value. In ancient Greece, for example, the "legitimacy" of money was a religious issue: "[a]11 Greek money was once sacred; it emanated from the priesthood, as did other generally valid concepts of measure referring to weight, size and time" (Simmel 1990:187).

Historically, this has also been the case with artisans and their products. Especially in early urban societies artisanship was one of the major occupations open to strangers. Here the credit should go to Weber for highlighting the connections between artisanship, strangeness, and magic:

The artisan is deeply immersed in magical encumbrances in the early stages of occupational differentiation. Every specialized art that is uncommon and not widely disseminated is regarded as a magical charisma.... Other elements of this early belief are that the bearers of this charisma are set off by taboos... from the community of ordinary people (peasants), and frequently that they are to be excluded from the ownership of land. One final element of this early belief in the magical charisma [was that]... [w]herever crafts had remained in the hands of ancient groups possessing raw materials, who had first offered their arts as intruders in the community and later offered their craftsmanship as individual strangers settled within the community, the belief in the magical nature of special arts condemned such groups to pariah status and stereotyped with magic their manipulations and their technology. (Weber 1964:98)

In a similar manner, the access of strangers to "secret" domains is more visible in ancient societies than in modern society. Lewis Coser (1972) has analyzed two striking cases where strangers are recruited to a domain that is kept closed to ordinary members of a group: the Court Jews of Baroque Germany, and the Christian renegades who served the sultans of the Ottoman Empire (as elite soldiers and political advisors). In fact, such practices are by no means limited to Germany and the Ottoman Empire. A more or less identical pattern can be observed in numerous other cases: the "slave soldiers" (Mamelukes) used by Islamic rulers of Egypt, Jewish advisors who were employed in the Muslim courts of medieval Spain, Swiss mercenaries who served French kings, Praetorian Guards of Roman emperors, and so on (Coser 1972:575). As Coser further notes, especially when political rulers try to maximize their powers with respect to other elements of power in their society (e.g., feudal retainers, estates, guilds, and so on), strangers, who are isolated from the indigenous population, who have no power base in the society, and who cannot threaten the sovereignty of the rulers turn out to be the best "allies."

It is, then, the peculiar form of the stranger's relation to the group that makes it possible that she/he is admitted to those domains that remain closed to other group members. Here we can observe the same configuration that we have observed in the case of the stranger-arbitrator. Strangers are given access to what Hughes (1971) has called "guilty knowledge," precisely because they are unable to make use of it. Their 
presence in the most "sensitive" zone of power in the group is possible precisely because they are believed to be "powerless."

Perhaps the most striking example of this configuration can be seen in the case of eunuchs who are accepted into the most "private" and "vulnerable" realms precisely because they are supposed to be unable to abuse this vulnerability. ${ }^{12}$ Eunuchs (derived from the Greek word that means "keeper of the bedside") have served political rulers in many ancient and medieval kingdoms and empires, including China, India, the Middle East, the Ottoman Empire, and the Roman Empire. It is worth noting that there is a mutual convergence between "eunuchood" and strangeness as in the case of most other "tasks" that are typically carried out by strangers. Just as taking interest from one's group members is forbidden in most societies (and therefore moneylending is left to strangers), most cultures ban the castration of a group member by another (although there have been important exceptions).

Clearly, this practice is closely related to the extraordinary tasks that can be assigned to a person once he is castrated. Such tasks show considerable variation. In the Mamluk Empire, for example, there were "the eunuchs of the portals, the eunuchs of the Gate of the Veil, the eunuchs of the barracks, eunuch cupbearers, eunuchs of the royal wardrobe, eunuchs of the royal treasury, and other eunuchs with various duties" (Marmon 1995:11). But in Islamic societies, as elsewhere, eunuchs were chiefly employed in the households of the kings and other higher officials. Their most prominent task was to manage and protect the "private" quarters of the palaces where even the highest officials of the emperors were not allowed.

Yet, in a sense, eunuchs did not truly "belong" to this inner core. Rather, they were its "guardians" who were placed between the inside and the outside. This point, as Marmon (1995) notes, comes to the fore in the 14th century poet and philosopher AlGhazali's treatise on the household (the compositional structure of which replicates the structure of a house). In this book, titled Book of the Risings of the Full Moons on the Dwellings of Joy, Al-Ghazali places the eunuchs not in the inner circles of a household but in the vestibule (the "waiting lounge").

The case of eunuchs reveals much about the connection between the symbolic and political dimensions of stranger-relations, and division of labor. As well known, Simmel notes that the stranger is often viewed as a person who lacks a "vital substance," adding that this "substance" might be purely symbolic or "metaphorical." Here the eunuch not only literally "lacks" something, but this lack-the very basis of the asymmetrical power relation between the stranger and the group - is directly related to the usefulness of the eunuch. The eunuch is extraneous to the group but in him the chaotic forces of the outside are rendered harmless. As such, not only does the eunuch, himself originally an "outsider," become all the more suitable for the task of protecting the inside from outside, but also works as an antidote against the alien forces that crawl within the very inside. Neither a full outsider, nor an insider, the eunuch becomes the police of limits and boundaries par excellence.

\section{DIRT AND "MODERN STRANGERS"}

Finally, we can talk about a fourth domain about which Simmel does not provide any examples (I will soon return to the reasons why this domain escapes Simmel's attention). This is the domain of what might loosely be called "dirty jobs."

\footnotetext{
${ }^{12}$ The literature on eunuchs is too large to be cited here. See, for example, Scholz (2001).
} 
First of all, we can talk about a rather direct link between dirt and strangeness. Thus, for example, although artisans in ancient societies often had a "magical charisma," especially in ancient Greece they were seen as practicing "banausic" labor, which implied that, in contradistinction to agricultural labor, this kind of work was done in closed, dark rooms, filled with polluted air (Pomeroy et al. 1999). More generally, "[b]y the fourth century $[\mathrm{BC}]$ the word banausia conveyed the idea of vulgarity, bad taste; and its 'technical' meaning was being discussed in 'philosophical circles' (Whitehead 1977:118). Both Plato and Aristotle condemned banausic labor; the latter argued that a good polis should never employ its citizens in this type of occupation.

We can easily extend this list with contemporary examples. The case of "guest workers" in western Europe, who, at least initially, were often employed in cleaning jobs (more on this below), is well known. So is the case of domestic workers and nannies from developing countries who are employed in wealthy households in the West, and whose major tasks include washing, cleaning, tidying up, and cookingtasks that other family members usually find "vulgar," dirty, or boring. ${ }^{13}$

More generally, it might be argued that the tasks that are assigned to strangers often involve objects that are deemed impure, even "evil," and it is the responsibility of the stranger to cleanse the group from those objects. The witchfinder cleanses the group from sorcerers; the arbitrator settles conflicts; the moneylender carries out a task that is viewed as "evil." 14 At the very least, such tasks are almost always viewed as being "unpleasant." Conversely, by performing such tasks, the stranger him/ herself appears as an impure being.

Perhaps the most vivid example of this interplay can be seen in the case of "untouchables" and their occupations. As Weber (1968:12) describes it in his study on India: ${ }^{15}$

The increase in population of wood and mountain barbarian tribes on one hand, and the increasing demand for labor in the developing culture areas on the other [,] created, with increasing wealth, numerous lower or unclean services. When the local resident population declined to take them over, these occupations fell into the hands of alien workers of foreign origin who were permanently lodged in urban areas but retained their tribal affiliations.

It is almost impossible not to note the striking resemblance between the situation that Weber describes in this passage and the situation of "guest workers" in presentday Europe.

\footnotetext{
${ }^{13}$ Although the term "dirty jobs" might bring to mind sex work, the social status of sex workers shows much variation across cultures. Moreover, while in many ancient societies sex work was often practiced by slaves, especially in contemporary societies migrant sex workers constitute a minority. There is no clear indication that sex work can be characterized as a special task that is predominantly carried out by strangers (Ruenkaew 2002). In fact, under certain circumstances, access to "local" sex workers is denied to strangers. This is closely related with the symbolic association between "home" and women (see, e.g., Douglas 1966, 1982). As Nirenberg (1996:156) observes in his study on the 14th century Crown of Aragon, the most violent reactions toward interfaith sexuality in this society concerned sex workers: "[T]he prostitute, available to all and denying none, can be thought of as the center of a circle, bound by radiating blood relations to all males with sexual rights in her.... [Thus] the prostitute's body might become the site of abjection, the place at which the 'self' (i.e., the collective group, ...) recognized and (ideally) rejected the 'other'...."

${ }^{14}$ Money is often seen as both a magical and a dirty object-a point that is also emphasized in contemporary psychoanalytic theory (Brown 1985).

${ }^{15}$ Although Weber's concept of "pariah people" is often criticized for its lack of coherence (see, e.g., Momigliano 1980), this critique is directed to his work on Judaism rather than Hinduism. Turner (1996) has pointed out that Weber's work on India shares a common ground with Orientalism. For a highly positive reappraisal of Weber's The Religion of India (1968), see Gellner (1995).
} 
The case of "guest workers" is indeed quite important for understanding the situation of strangers in modern society. Although the relation of the stranger to dirt has almost a universal nature, it seems to be all the more emphasized in the 20th century, overshadowing all other attributes of strangers, such as mobility and neutrality. No doubt, the most paradigmatic example of the stranger in the 20th century has neither been the "trader," nor the "judge," nor even the "confidant" but the migrant worker who performs unskilled, manual labor. In fact, today, this image seems to be increasingly replaced by the refugee who is kept in closely scrutinized asylums, or the illegal immigrant who hides in containers in commercial ships or who crosses borders, crawling under barbed wires in the dark.

Simmel was partly aware of this historical transformation. In The Philosophy of Money, he wrote: " 'strangers' in the original sense no longer exist today ..." (Simmel 1990:227). Referring particularly to changes in modern economic systems, he noted that "[m]oney has not lost the character that made it a domain of the stranger, but has intensified it more and more into abstraction and colourlessness.... The contrast that existed between the native and the stranger has been eliminated, because the money form of transactions has now been taken up by the whole economic community" (Simmel 1990:227; emphasis mine).

For Simmel, the disappearance of "strangers" in the "original" sense is not merely about the disappearance of their unique role in the financial sector. In "The Metropolis and Mental Life," a highly renowned essay published five years before the excursus on the stranger, Simmel (1971b) describes the average urbanite of his time as someone who is bound to systematically ignore the unique features of his/her fellow metropolitans and focus on their more general characteristics - that is, to treat them as "types" of strangers. All the characteristics that Simmel attributes to the stranger, such as lack of organic ties with a community and high spatial mobility, are mentioned here, except that this time they are not attributed to a specific individual or group but to everyone living in modern societies.

In the light of the above discussion, it is possible to specify two distinct, though closely interrelated, problems that should be tackled in conceptualizing strangerrelations in modern society. The first concerns the question of whether one can treat "the stranger" as a legitimate sociological category any longer. If, as Simmel seems to argue, the modern individual displays most of the characteristics attributed to the stranger, should we not conclude that there are no strangers in contemporary society because "we are all strangers now"? While many contemporary theorists who at least implicitly entertain this possibility do not go as far as to abandon the concept of the stranger, there has nevertheless been a tendency to view the stranger as an ambiguous social category, that cannot be defined in terms of exclusion or externality to a well-specified "native" community: that the stranger is "within", rather than "without"; that "we are strangers to ourselves;" that negative reactions toward strangers often stem from a fear of the self, and so on, are ideas that are frequently repeated in many recent works (Bauman 1991; Derrida 2000; Girard 1986; Kristeva 1991; Räthzel 1995).

These ideas are not new-Simmel (1971a) had already pointed out that even the most intimate relations involve a trace of strangeness. However, the emphasis is new, and it might not be a coincidence that it emerges in a context where the classic distinctions between the stranger and the "native" have become more and more difficult to sustain. It also seems that as the distinction between the stranger and the native begins to disappear, so does the distinction between the stranger and the other. It might even be argued that in the contemporary literature, the two concepts 
tend to become almost indistinguishable, as the "stranger" is used more and more in a metaphorical sense. ${ }^{16}$

The second problem, which follows partly from the first, is related to the question of whether the modern era has produced a new stranger, and if so, in what form? Writing at the dawn of the 20th century, Simmel was completely silent about these questions. It is probably this silence that led some of his commentators to argue that the conceptual framework he developed could only be applied to "traditional" strangers and was quite useless in dealing with the "modern stranger." Thus, Harman (1988) suggests that in stark contrast with the stranger in premodern societies, modern strangers are those who seek "community" in a world where formal, impersonal, and distanced relations between people have become the norm (as, e.g., in the case of a person who migrates to a big city from a small town). On a different note, Zygmunt Bauman (1991) turns the notion of the stranger into a metaphor and extends its usage by "applying" it to groups such as the "new poor," who are an integral part of late modern societies but who cannot enjoy the fruits of "consumption society." 17

While Harman's and Bauman's conceptualizations draw attention to new configurations of stranger-relations that are not observed in the classical literature, perhaps the most paradigmatic example of the stranger in the 20th century has been the much discussed case of what might be loosely called the "postcolonial stranger." In fact, I believe the absence of the theme of "dirt" and the issue of modern strangers in Simmel's work has much to do with his unawareness of modern colonialism, which is probably a result of his geographic distance from colonial contexts. For colonialism is precisely that historical process that makes, to use Simmel's (1990:227) words, "remote countries" near-by binding them economically, politically, and culturally to the "center"-while at the same time preserving their peripheral status. It is also this process that creates those hundreds of millions of people who are "included" in a worldwide socioeconomic system but who nevertheless remain outside it and confront it. As such, despite the significant differences in the historical context, the (post)colonial stranger is structurally identical to Simmel's conception, which was mostly based on premodern examples.

The postcolonial stranger appears in two guises and at two different, but inseparable levels. At a global level, the postcolonial stranger can be viewed as the citizen of a postcolonial nation. It might even be argued that the "Third World" of the cold-war era was, if not still is, a kind of global ghetto. At a local or "national" level postcolonial strangers are the immigrants who have migrated either to the metropoles of old colonial powers from previous colonies, or, as in the case of immigration to

\footnotetext{
${ }^{16}$ While a full discussion of the various senses in which the category of "the other" is used in modern social thought is beyond the scope of our discussion (see Otnes 1997), it is worth noting that, for Simmel, strangeness refers to a very specific form of otherness that is based on extraneousness or "alien origin." At the same time, stranger-relations epitomize the tension between distance and nearness that permeates all social relations: "all personal relations whatsoever can be analyzed in terms of this scheme." (Simmel 1971a:146). In other words, otherness as a fundamental, yet often hidden, dimension of social life takes on a visible form in stranger-relations.

${ }^{17}$ Bauman's conceptualization of the stranger has gone through a series of changes. In Modernity and the Holocaust (1989), Bauman's conception is based on the experience of European Jews, which is also the "classical" example in much of the early sociological literature (Karakayali 2003a, 2003b). In Modernity and Ambivalence (1991), however, the stranger takes on a metaphorical sense, signifying ambivalence and indetermination in social relations. Let me note that, despite appearances, Bauman's thesis does not directly follow from Simmel's work. Although Simmel underlines that strangers are not merely outsiders, there is no indication in his text that they should therefore be characterized as ambivalent. At times, Bauman himself seems to oscillate between presenting the ambivalence of the stranger as an objective fact and as an attributed quality. For an overview of Bauman's works on the stranger, see Marotta (2000, 2002). See also Diken (1998).
} 
North America, they arrive to a newly colonized land from the poorer or troubled regions of the world.

This point is crucial for understanding both the similarities and differences between "old" and "new" strangers. In preindustrial societies, the stranger appears as a modernizing element. In such societies, strangers are assigned to the most unorthodox and uncommon tasks that often require special skills; they are far more mobile, and often more "objective" and "rational" than the natives. ${ }^{18}$ In modern society, the stranger goes through a metamorphosis (Karakayali 2003a). The "modern stranger," especially in the guise of the postcolonial stranger, appears to be far too "traditional," too "backward," too community oriented, too little educated, and unskilled. Modern strangers often take upon themselves the most primitive, the most "common," in short, the "dirtiest" tasks.

It might even be argued that, in purely analytical terms, one can identify two types of strangers. The first type is highly skilled, and is accepted to the group in order to carry out tasks that the natives are incapable of performing. The second type, lacking special skills, is employed in the most "ordinary" tasks that the natives are unwilling to perform. Although, as we have seen, in reality these two types often blend into each other, in the modern age, it seems, the latter type has become more predominant.

\section{CONCLUSION}

In concluding this study, I would like to sketch out some of the broader implications of the above observations for a general theory of stranger-relations.

First of all, although the presence of strangers in a society is often-and quite rightly-associated with social and cultural diversity, in the light of the above discussion, it might be argued that this presence has a more complex effect on processes of social differentiation. On the one hand, the stranger plays a "unifying" role. We can isolate two distinct modes in which this role is played out. First, the stranger "unifies" by linking the separate elements of the group, most notably through his/her activities in circulation and arbitration. Second, the stranger unifies by taking on a special task and, thereupon, hindering a further division in the group, most notably through his/her activities in secret or dirty domains. In fact, in many cases, these two different modes overlap since the "special task" consists of linking the separate parts (as, most notably, in the case of traders in ancient societies).

As such, the logic of strangeness is comparable to the counterintuitive logic that informs Simmel's analysis of "money." Like money, which has no intrinsic value, the stranger is a "supernumerary" who has no intrinsic "place." And just as money, precisely because it is not an "object" like others, can facilitate the exchange of other objects, the stranger, precisely because she/he is not deeply rooted in the group, is capable of unifying it. In this sense, strangers do not exactly constitute a separate group or class; rather, strangeness involves a "super-division" that works above (or below) other divisions in the group. In most societies, strangers usually operate either as a super-, or inter-, or underclass (or all of them at the same time).

Seen in the light of Simmel's exposition, then, the formation of strangerrelations implies the opening of a new dimension (a "super-dimension") that works "asymptotically" with respect to existing divisions. This point can be further clarified

\footnotetext{
${ }^{18}$ Sombart (1982) has argued that it was precisely this modern outlook of the stranger that turns him/her into an "irritating" figure in premodern contexts.
} 
by paying close attention to the characterization of strangers as "parasites" circulating a "host" body. Simmel's (1971a:144) observation that "[a]ny closed economic group where land and handicrafts have been apportioned in a way that satisfies local demands will still support a livelihood for the trader" implies a partly "parasitic" existence. However, this "parasitism" should be understood in the sense that Michel Serres (1982) has given it: not simply as taking something without paying back, but as the invention of a new regime of exchange and communication. One might say that strangers as circulatory agents do not "produce" anything; they do not exchange something they have produced for another product. Yet they endow the already produced products with a new sense and a new mobility. Similarly, strangers in the role of teachers and translators do not produce the information they circulate but they restructure and interpret that information in accordance with the needs of their "customers."

However, I need to add that this "new dimension" that emerges as a result of the stranger's involvement in the group might also create an opposite effect by triggering hitherto hidden potentials in a society and, thus, leading to new social divisions. Above, I have noted that Simmel conceptualizes forms of interaction as tools that are used in the realization of certain interests, or, more generally, as solutions to certain problems. The term "solution," however, should not lead us to think that a form of interaction is an atemporal, once-for-all closure to a problem, a point that Simmel himself often stresses. Once they emerge, forms of interaction gain a certain autonomy. The most important implication of this autonomy is that once a certain form of relationship is sustained in a society, it can be utilized for all sorts of purposes for which it was not originally intended. Like all "means," forms of interaction have unintended consequences: "often ... a relationship among individuals which was originally established for a particular purpose grow[s] beyond this and become[s] the bearer of altogether different contents...." (Simmel 1990:212).

While it is beyond the scope of this article to provide an analysis of the "unintended consequences" of stranger-relations, it is important to emphasize that such relations are no exception to the principle stated by Simmel-as, for example, in the case of outsiders who are accepted to a society to serve the interests of powerful groups, but who eventually form alliances with other factions and/or become involved with tasks other than the originally intended. ${ }^{19}$

A second point worth noting is that although the "use" of the stranger is only one aspect of stranger-relations, it might constitute an essential starting point for comprehending what is unique about strangeness as a social relation. All the examples I have considered above indicate that many domains and activities that remain open to natives are closed to strangers while the domains that remain open to strangers are usually closed to other group members. Expressed in relational terms, we might state that what one can do with/to other members of one's group, one cannot do with/to strangers, but also, one can do things with/to strangers that one cannot do with others. The assignment of strangers to "special tasks" should be seen as a specific instance of this general logic.

These points might also have significance for the study of division of labor in general. Historically, division of labor has been of interest to theorists for a variety of reasons, ranging from a concern with the growth and distribution of wealth

\footnotetext{
${ }^{19}$ The history of Janissaries is a case in point. While Coser (1972) is right in noting that this elite army of the sultans was initially constituted from Christian renegades, he fails to note that eventually Janissaries formed alliances with the political rivals of the sultanate.
} 
to more "sociological" concerns such as social change and order, and, more recently, distribution of power and technological change (Garnsey 1981; Rueschemeyer 1994). Despite this variation, one common aim in the literature has been the identification of the mechanisms that trigger changes in the division of labor. The case of the stranger reveals one such mechanism: even a self-sufficient socioeconomic system where "all the positions are occupied" can have room for "extraneous" elements and be transformed in unexpected ways as a result of this "addition."

Finally, a note of precaution: although the "usefulness" of the stranger implies a "functional" dimension, we should refrain from concluding that the stranger and the native "complement" each other and form an harmonious whole. In essence, strangeness is an unstable relation since the possibility of expulsion or assimilation always remains intact. But even when relations with strangers do not dissolve into these extremes, strangeness involves, to use Simmel's (1971a) words, "dangerous possibilities." Certain things that one can do to strangers-things that one is not supposed to do to other members of one's group - are far from being pleasant. The case of eunuchs indicates that the living bodies of strangers can easily be "shaped" according to the desires of the powerful groups in society. The political vulnerability of the stranger, then, can easily be accompanied by a bodily as well as a spiritual "malleability." In such instances (most vividly in the case of eunuchs), the stranger is not much distinguishable from a "pet" or a "guinea pig."

It may be that such practices are rather rare and officially condemned in most contemporary societies. Yet, can we assume that the "malleability" of the stranger is an idea that is entirely alien to the modern world? In any case, it is important to remember that the "usefulness" of the stranger is not merely an abstract sociological function; it also entails "being used" and resistance to such "uses." This means strangeness is inherently a political and ethical relation, but it also means that any political and ethical consideration of this relation, would be lacking without a conceptual framework that takes into account the role of strangers in the social division of labor.

\section{REFERENCES}

Alexander, J. C. 2004. "Rethinking Strangeness: From Structures in Space to Discourses in Civil Society." Thesis Eleven 79:87-104.

Almack, R., L. A. Cook, and F. Greenhoe. 1938. "Teacher and Community Relations.” American Sociological Review 3:167-74.

Bauman, Z. 1987. Legislators and Interpreters: On Modernity, Post-Modernity, and Intellectuals. Ithaca, NY: Cornell University Press.

1989. Modernity and the Holocaust. Ithaca, NY: Cornell University Press.

1991. Modernity and Ambivalence. Ithaca, NY: Cornell University Press.

Bercovitch, J. and A. Houston. 1996. "The Study of International Mediation: Theoretical Issues and Empirical Evidence.” Pp. 11-35 in Resolving International Conflicts: The Theory and Practice of Mediation, edited by J. Bercovitch. London: Lynne Rienner.

Bonacich, E. 1973. “A Theory of Middlemen Minorities.” American Sociological Review 38:583-94.

Bourdieu, P. and L. J. D. Wacquant. 1992. An Invitation to Reflexive Sociology. Oxford: Polity.

Brown, N. O. 1985. Life Against Death: The Psychoanalytical Meaning of History, 2nd ed. Hanover: Wesleyan University Press.

Calavita, K. 1994. "U.S. Immigration and Policy Responses: The Limits of Legislation.” Pp. 55-82 in Controlling Immigration: A Global Perspective, edited by W. A. Cornelius, P. L. Martin, and J. F. Hollifield. Stanford, CA: Stanford University Press.

Colson, E. 1966. "The Alien Diviner and Local Politics Among the Tonga of Zambia." Pp. 221-28 in Political Anthropology, edited by M. Swartz, V. Turner, and A. Tuden. Chicago, IL: Aldine. 
Coser, L. 1972. "The Alien as a Servant of Power: Court Jews and Christian Renegades." American Sociological Review 37:574-81.

Curtin, P. D. 1992. Cross-Cultural Trade in World History. New York: Cambridge University Press.

Derrida, J. 2000. Of Hospitality. Stanford, CA: Stanford University Press.

Diken, B. 1998. Strangers, Ambivalence and Social Theory. Aldershot: Ashgate.

Douglas, M. 1966. Purity and Danger: An Analysis of the Concepts of Pollution and Taboo. London: Routledge and Kegan Paul. 1982. Natural Symbols: Explorations in Cosmology. New York: Pantheon.

Durkheim, E. 1964. The Division of Labor in Society. New York: Free Press.

Fraser, A. M. 1992. The Gypsies. Oxford: Blackwell.

Frisby, D. 1981. Sociological Impressionism: A Reassessment of Georg Simmel's Social Theory. London: Heinemann.

-1992. Simmel and Since: Essays on Georg Simmel's Social Theory. London: Routledge.

Garnsey, E. 1981. "The Rediscovery of Division of Labor." Theory and Society 10(3):337-58.

Gellner, D. N. 1995. "Max Weber, Capitalism, and the Religion of India." Pp. 21-46 in Religion and the Transformation of Capitalism, edited by R. Roberts. London: Routledge.

Girard, R. 1986. The Scapegoat. Baltimore, MD: Johns Hopkins University Press.

Habermas, J. 1996. "Georg Simmel on Philosophy and Culture: Postscript to a Collection of Essays." Critical Inquiry 22:404-14.

Harman, L. D. 1988. The Modern Stranger: On Language and Membership. Berlin: Mouton de Gruyter.

Hechter, M. 1978. "Group Formation and the Cultural Division of Labor." American Journal of Sociology 84(2):293-318.

Hughes, E. C. 1928. "Personality Types and the Division of Labor." American Journal of Sociology 33(5):754-68.

1971. The Sociological Eye. Chicago, IL: Aldine-Atherton.

Jordan, W. C. 1997. "Home Again: The Jews in the Kingdom of France, 1315-1322." Pp. 27-45 in The Stranger in Medieval Society, edited by F. Akehurst and S. C. van D'Elden. Minneapolis, MN: University of Minnesota Press.

Kaern, M., B. S. Philips, and R. S. Cohen, eds. 1990. Georg Simmel and Contemporary Sociology. Dordrecht: Kluwer Academic.

Karakayali, N. 2003a. "Metamorphoses of the Stranger: Jews in Europe, Polish Peasants in America, and Turks in Germany." New Perspectives on Turkey 28/29:37-59.

2003b. Simmel's Stranger: In Theory and in Practice. Unpublished Ph.D. thesis, University of Toronto, Toronto.

- 2004. "Reading Bourdieu with Adorno: The Limits of Critical Theory and Reflexive Sociology." Sociology 38(2):351-68.

Kristeva, J. 1991. Strangers to Ourselves. New York: Columbia University Press.

Leighton, N. O. 1979. "The Political Economy of a Stranger Population: The Lebanese of Sierra Leone." Pp. 85-104 in Strangers in African Societies, edited by W. Shack and E. Skinner. Berkeley, CA: University of California Press.

Levine, D. N. 1977. "Simmel at a Distance: On the History and Systematics of the Sociology of the Stranger." Sociological Focus 10(1):15-29.

Marmon, S. 1995. Eunuchs and Sacred Boundaries in Islamic Society. Oxford: Oxford University Press.

Marotta, V. 2000. "The Stranger and Social Theory." Thesis Eleven 62:121-34.

_. 2002. "Zygmunt Bauman: Order, Strangerhood and Freedom." Thesis Eleven 70:36-54.

McLemore, S. D. 1970. "Simmel's 'Stranger': A Critique of the Concept." Pacific Sociological Review 13(2):86-94.

Momigliano, A. 1980. "A Note on Max Weber's Definition of Judaism as a Pariah-Religion." History and Theory 19(3):313-18.

Münz, R. and R. Ulrich. 1998. "Germany and its Immigrants: A Socio-Demographic Analysis.” Journal of Ethnic and Migration Studies 24(1):25-56.

Nirenberg, D. 1996. Communities of Violence: Persecution of Minorities in the Middle Ages. Princeton, NJ: Princeton University Press.

Oakes, G., ed. 1980. "Introduction." Pp. 3-94 in Essays on Interpretation in Social Science, by Georg Simmel.Totowa, NJ: Rowman and Littlefield.

Otnes, P. 1997. Other-Wise: Alterity, Materiality, Mediation. Oslo: Scandinavian University Press.

Pels, D. 1999. "Privileged Nomads: On the Strangeness of Intellectuals and the Intellectuality of Strangers." Theory, Culture and Society 16(1):63-86.

Poggi, G. 1993. Money and the Modern Mind: Georg Simmel's Philosophy of Money. Berkeley: University of California Press. 
Pomeroy, S. B., S. M. Burstein, W. Donlan, and J. T. Roberts. 1999. Ancient Greece: A Political, Social, and Cultural History. New York: Oxford University Press.

Princen, T. 1992. Intermediaries in International Conflict. Princeton, NJ: Princeton University Press.

Räthzel, N. 1995. "Images of Heimat and Images of 'Ausländer'." Pp. 45-70 in Negotiating Identities: Essays on Immigration and Culture in Present Day Europe, edited by A. Ålund and R. Granqvist. Amsterdam: Rodopi.

Ruenkaew, P. 2002. “The Transnational Prostitution of Thai Women to Germany." Pp. 69-85 in Transnational Prostitution: Changing Patterns in a Global Context, edited by S. Thorbek and B. Pattanaik. New York: Zed Books.

Rueschemeyer, D. 1994. "Variations on Two Themes in Durkheim's 'Division du travail': Power, Solidarity, and Meaning in Division of Labor." Sociological Forum 9(1):59-71.

Scholz, P. O. 2001. Eunuchs and Castrati: A Cultural History. Princeton, NJ: Markus Wiener Publishers.

Serres, M. 1982. The Parasite. Baltimore, MD: Johns Hopkins University Press.

1983. Hermes: Literature, Science, Philosophy. Baltimore, MD: Johns Hopkins University Press.

Shack, W. A. 1979. "Open Systems and Closed Boundaries: The Ritual Process of Stranger Relations in New African States.” Pp. 37-47 in Strangers in African Societies, edited by W. Shack and E. Skinner. Berkeley, CA: University of California Press.

Shack, W. A. and E. Skinner, eds. 1979. Strangers in African Societies. Berkeley, MD: University of California Press.

Simmel, G. 1908. Soziologie: Untersuchungen über die Formen der Vergesellschaftung. Leipzig: Duncker \& Humblot.

- 1950. "Superordination and Subordination." Pp. 181-303 in The Sociology of Georg Simmel, edited by K. H. Wolff. New York: Free Press.

- 1971a. "The Stranger." Pp. 143-50 in Georg Simmel: On Individuality and Social Forms, edited by D. N. Levine. Chicago, IL: University of Chicago Press.

. 1971b. "The Metropolis and Mental Life." Pp. 324-40 in Georg Simmel: On Individuality and

Social Forms, edited by D. N. Levine. Chicago, IL: University of Chicago Press.

1971c. "Conflict." Pp. 70-95 in Georg Simmel: On Individuality and Social Forms, edited by

D. N. Levine. Chicago, IL: University of Chicago Press.

1971d. "The Problem of Sociology." Pp. 23-35 in Georg Simmel: On Individuality and Social

Forms, edited by D. N. Levine. Chicago, IL: University of Chicago Press.

1977. The Problems of the Philosophy of History: An Epistemological Essay. Translated and edited

by G. Oakes. New York: Free Press.

1980. Essays on Interpretation in Social Science. Translated and edited by G. Oakes. Totowa, NY:

Rowman and Littlefield.

. 1990. The Philosophy of Money, 2nd enlarged ed. London: Routledge and Kegan Paul.

Sombart, W. 1982. The Jews and Modern Capitalism. New Brunswick: Transaction.

Turner, B. S. 1996. For Weber: Essays on the Sociology of Fate. London: Sage Publications.

Wallace, R. A. and S. Hartley. 1988. "Religious Elements in Friendship: Durkheimian Theory in an Empirical Context." Pp. 93-106 in Durkheimian Sociology: Cultural Studies, edited by J. C. Alexander. Cambridge, UK: Cambridge University Press.

Weber, M. 1964. The Sociology of Religion. Boston, MA: Beacon Press.

1968. The Religion of India: The Sociology of Hinduism and Buddhism. Translated and edited by

H. H. Gerth and D. Martindale. New York: Free Press. Press.

1975. Roscher and Knies: The Logical Problems of Historical Economics. New York: Free Press.

Whitehead, D. 1977. The Ideology of the Athenian Metic. Cambridge: Cambridge Philological Society.

Wood, M. M. 1934. The Stranger: A Study in Social Relationships. New York: Columbia University Press. 1953. Paths of Loneliness. New York: Columbia University Press. 